\title{
Development of a scale to assess the diurnal impact of insomnia
}

\author{
Cristina Ruiz ${ }^{\mathrm{a}, \mathrm{b}, *}$, Georgina Guilera ${ }^{\mathrm{c}}$, Juana Gómez-Benito ${ }^{\mathrm{c}, \mathrm{d}}$ \\ a Teknon Medical Centre, Barcelona, Spain \\ b Catalonian Open University, Barcelona, Spain \\ c Department of Methodology of the Behavioural Sciences, Faculty of Psychology, University of Barcelona, Spain \\ d Institute for Brain, Cognition and Behaviour, University of Barcelona, Spain
}

\section{A R T I C L E I N F O}

\section{Article history:}

Received 8 October 2010

Accepted 8 May 2011

\section{Keywords:}

Daytime impact

Insomnia consequences

Sleep disorders

Psychometric properties

Assessment

\begin{abstract}
A B S T R A C T
The objective of this study was to develop and validate a scale to assess the diurnal impact of insomnia. The Insomnia Diurnal Impact Scale (IDIS) comprises six items designed to evaluate the daytime effects of insomnia. The psychometric properties of the original scale were analysed in a sample of 172 students, while its ability to differentiate insomniacs and non-insomniacs (according to the International Classification of Diseases (ICD)-10 criteria) was examined in a sample of 79 psychiatric patients and 82 individuals from the community. The psychometric properties of the English version were then analysed in a sample of 44 Englishspeaking participants. The results showed the internal consistency coefficient to be very good $(0.86)$, with test-retest reliability at 1 month being 0.79 . A single factor explained almost $60 \%$ of the variance. Correlation of the IDIS with other scales varied between moderate and high values. Sensitivity was $78 \%$ and specificity $57 \%$ in the community sample, while the corresponding figures for the psychiatric population were $83 \%$ and $63 \%$. Cronbach's $\alpha$ coefficient for the English version reached a value of 0.93 . These results indicate that the IDIS shows adequate reliability and validity with both general and psychiatric populations, and also that it can discriminate between the presence and absence of insomnia. The English version presents good preliminary results regarding item-corrected total correlation and internal consistency. In conclusion, the IDIS appears to be a useful tool in the primary care and mental health contexts for assessing insomnia-related diurnal dysfunction.
\end{abstract}

(c) 2011 Elsevier Ireland Ltd. All rights reserved.

\section{Introduction}

Insomnia is one of the most prevalent health problems in the general population worldwide and can be defined as either a symptom or a disorder. As a disorder it is characterised not only by the symptoms of insomnia but also by difficulties in daily functioning. According to DSM-IV-TR (American Psychiatric Association, 2000) and the International Classification of Sleep Disorders (ICSD-2) (American Academy of Sleep Medicine, 2005), a diagnosis of insomnia is only made when poor-quality sleep is accompanied by a deterioration in daytime functioning. Several authors (Morin, 1993; Zammit et al., 1999; Alapin et al., 2000; Morin, 2000) report that individuals with insomnia not only experience greater difficulty sleeping during the night, but also perceive themselves to be less capable during the day, particularly with respect to symptoms of fatigue, sleepiness, concentration and irritability. In this context, many authors have stated that those who suffer from insomnia present signs

\footnotetext{
* Corresponding author at: Centro Médico Teknon, Consultorios - Despacho 56, Marquesa de Vilallonga, 12, 08017 Barcelona, Spain. Tel.: + 34 932906456; fax: + 34 932546780.

E-mail addresses: cris.ruiz@terra.es, cruizc@uoc.edu (C. Ruiz), gguilera@ub.edu (G. Guilera), juanagomez@ub.edu (J. Gómez-Benito).
}

of psychological maladjustment, such as anxiety and depression, during the day (Morin et al., 1993; Breslau et al., 1996; Zammit et al., 1999, Alapin et al., 2000; American Psychiatric Association, 2000).

The current belief that diurnal factors play a key role in the maintenance of sleep disorders has been corroborated by professionals in the field, who argue that research into this disorder should include the assessment of its diurnal impact on the patient. Harvey (2002), in her cognitive model of insomnia, claims that diurnal processes are as important as those which operate during the night. Support for this view was provided by Ellis and colleagues (Ellis et al., 2007), who found that individuals suffering from insomnia tended to focus on the diurnal consequences of non-refreshing sleep.

The quality of sleep has been routinely measured using objective tests such as polysomnographs and actigraphs, as well as more subjective tests such as medical interviews, sleep diaries and questionnaires. Questionnaires or scales enable a number of different assessments to be made, for example, of sleep deterioration, somnolence or the patient's attitude when going to bed. However, the diurnal impact of insomnia has not traditionally been the main objective of sleep professionals, and the majority of available scales mainly evaluate the nocturnal particularities of the sleep disorder. This is despite the fact that the greatest distress reported by sufferers concerns the difficulty in performing throughout the day. 
Of all the standardised psychometric instruments developed to assess insomnia, there are a limited number which do include items addressing diurnal factors. For example, the Pittsburgh Sleep Quality Index (PSQI; Buysse et al., 1989) has a subscale of daytime dysfunction, the Leeds Sleep Evaluation Questionnaire (LSEQ; Parrott and Hindmarch 1978) dedicates two items to the evaluation of diurnal aspects such as sleepiness and the eight-item version of the Athens Insomnia Scale (AIS-8; Soldatos et al., 2000) has three items about diurnal impact. However, while these questionnaires do seek to address factors other than nocturnal ones, they are not specific to the diurnal problem and do not explore in depth the daytime impact of insomnia.

A few standardised tools have centred solely on the diurnal consequences of insomnia but they are limited as they tend to measure only one or two aspects of what individuals experience during the day. For example, Hoddes and colleagues (Hoddes et al., 1973) developed the Stanford Sleepiness Scale (SSS), which only evaluates the subjective perception of daytime sleepiness, as does the Epworth Sleepiness Scale (ESS; Johns, 1991), which assesses the perception of sleepiness in adults. More recently, another group of researchers investigated the consequences of insomnia in daily tasks and constructed a new assessment instrument, the Flinders Fatigue Scale (Gradisar et al., 2007). This scale, which evaluates daytime fatigue, goes one step further in discriminating between sleepiness and fatigue.

In conclusion, the lack of suitable tools covering the different aspects of the diurnal impact of insomnia, added to the growing concern expressed by sleep professionals, reinforces the need to assess this problem adequately so as to identify more specific intervention strategies and assess their effectiveness in diurnal dysfunction. The objective of the present study was therefore to develop a brief scale to assess the diurnal impact of insomnia and to examine its reliability and validity. To this end, the study was conducted in four consecutive phases: description of the scale's development (phase 1), its psychometric properties (phase 2), its diagnostic validity (phase 3 ) and the development of an English version of the scale (phase 4).

\section{Phase 1: Development of the Insomnia Diurnal Impact Scale}

\subsection{Item generation}

Bearing in mind that the new scale has to measure the construct 'diurnal impact of insomnia', an extensive literature review of standardised instruments, informal questionnaires and interviews, focussing mainly on insomnia and its consequences, was first carried out. The databases Pubmed, Medline, PsycInfo and New Abstracts and Papers in Sleep (NAPS) were used to find articles related to the construct of interest, the combined keywords being insomnia, insomnia consequences, daytime impact, assessment and questionnaire. Questionnaires and interviews used in research or clinical practice in various medical health centres were also compiled. The questionnaires checked were the following: Insomnia Interview Schedule (Morin, 1993), Sleep Impairment Index (Morin, 1993), Beliefs and Attitudes about Sleep Scale (Morin, 1993), AIS-8 (Soldatos et al., 2000), Epworth Sleepiness Scale (ESS; Johns 1991), Stanford Sleepiness Scale (SSS; Hoddes et al., 1973), Pittsburgh Sleep Quality Index (PSQI; Buysse et al., 1989), Leeds Sleep Evaluation Questionnaire (LSEQ; Parrott and Hindmarch, 1978) and the Flinders Fatigue Scale (Gradisar et al., 2007). Additional informal material was also obtained from 10 medical health institutions in the UK and Spain (i.e., Sleep Disorders Centre, St Thomas's Hospital, UMDS, London; Guy's Hospital, London; The Institute of Psychiatry, London; Hither Green Hospital, London; Department of Psychological Medicine, Gartnavel Royal Hospital, Glasgow; St Bartholomew's Hospital, Kent; Neurology Department, Hospital Ramón y Cajal, Madrid; Neurology Department, Hospital Valle Hebrón, Barcelona; Sleep Clinic Dexeus, Barcelona and Hospital de la Santa Creu, Vic.) Finally, the diagnostic criteria of the Diagnostic and Statistical Manual of Mental Disorders (DSM-IV; American Psychiatric Association, 2000) and the Classification of Mental and Behavioural Disorders (ICD-10; World Health Organization, 1994) were also taken into account.

Based on all these sources of information, an initial screening of items was carried out. Specifically, those items which referred solely to the diurnal impact of insomnia were retained, while items that did not specifically refer to any type of consequences of insomnia were discarded.

\subsection{Content validity}

Initially, 15 items covering the different diurnal consequences of a sleep problem were generated in question format. These were subsequently presented to a panel of 11 judges; in this case, clinical psychologists who frequently worked with insomnia problems. The judges were asked to decide whether each item reflected the diurnal impact of insomnia, and to indicate on a scale of 1-5 (where $1=$ very little and $5=\mathrm{a}$ lot) the capacity of the item to measure the impact of insomnia. When there was no majority agreement among the judges (set at $>70 \%$ ) regarding whether an item assessed diurnal consequences, the item in question was discarded. A mean score was subsequently taken for the remaining items. The next criterion applied was to discard those items with a mean score below 4, which led to two further items being eliminated. However, although the item "For the last month or longer, I have generally felt sleepy throughout the day" obtained a score of 3.8, it was maintained because it measured a fundamental content of the diurnal impact of insomnia: daytime sleepiness. By contrast, another item which asked if the subject was taking medication was eliminated despite its score being above 4 , in this case because the judges considered that it would be necessary to specify the type of medication used were this item to be included. Based on the judges' comments, the items were then reformulated as statements rather than questions, and a scoring system was established using a scale of $0-3$, where $0=$ totally disagree, $1=$ disagree, $2=$ agree and $3=$ totally agree.

After this content validity analysis, a preliminary version of the questionnaire was developed, based on 12 statements regarding the daytime impact of insomnia.

\subsection{Item-corrected total score correlation}

The ability of the 12 items to differentiate between individuals with low scores and those with high scores was assessed by computing the correlation between each item score and the corrected total test score. To this end, a pilot study was carried out with 72 participants drawn from a sample of university students, psychiatric out-patients and a community population with and without a complaint of insomnia. A minimum threshold of 0.30 was stipulated and any items with lower values were removed from the questionnaire. This led to a further six items being eliminated, while the remaining six items constituted the final version of the questionnaire, the IDIS (IDIS; see Appendix 1a).

\section{Phase 2: Psychometric properties of the IDIS}

\subsection{Overview}

The objective of this phase of the study was to explore the psychometric properties of the IDIS in a sample of university students; the aspects examined being its internal consistency, factor extraction, item-corrected total correlation, temporal stability/test-retest reliability and criterion-related validity.

\subsection{Methods}

\subsubsection{Participants and procedure}

A total of 172 students from the University of Barcelona (36 men and 136 women) participated in the study. The overall mean age of the sample was 20.75 years (S.D. $=3.99$; range 1757 ), the means for 
men and women being 21.28 (S.D. $=2.49$ ) and 20.62 (S.D. $=4.28$ ), respectively.

As the IDIS attempts to measure the diurnal impact of insomnia and there is known to be a clear correlation between insomnia and mood state, the presence of anxiety disorders and effects on the general health of insomniacs, four other questionnaires (see subsection Instruments), in addition to the IDIS, were administered to the sample in order to assess the criterion-related validity of the scale. All these scales were administered to participants in the corresponding lecture rooms. Participation was voluntary and students did not receive any academic or monetary reward. Less than $3 \%$ of the students refused to participate. After being informed of the anonymity and confidentiality of data, individuals gave their informed consent to participate in the study. A group of 32 students was then assessed again 4 weeks later, employing a code which enabled the questionnaires to be paired without identifying the participants.

\subsubsection{Instruments}

The IDIS is a new scale designed to evaluate the diurnal consequences of insomnia. It comprises six polytomous items with a response format of 4 points, from 0 (total disagreement) to 3 (total agreement). The total score therefore ranges between 0 and 18 . The Beck Depression Inventory (BDI; Beck et al., 1979) is a self-administered questionnaire consisting of 21 items with four response options, and it evaluates symptoms of depression in individuals. The Beck Anxiety Inventory (BAI; Beck et al., 1985) also has 21 items with four response options (from none to serious), and it assesses the severity of anxiety symptoms. The General Health Questionnaire, 12-item version (GHQ12; Goldberg, 1972) is a self-administered questionnaire designed to identify common mental disorders among medical patients and community samples. Finally, the Athens Insomnia Scale (AIS; Soldatos et al., 2000) is an eight-item self-administered questionnaire created to assess sleep disturbance. It is based on the diagnostic criteria of ICD-10.

\subsubsection{Data analysis}

The internal consistency of the IDIS was evaluated by computing Cronbach's $\alpha$ coefficient, with item-corrected total correlations being obtained for each of the items. The dimensionality of the scale was examined by means of a principal components analysis. The temporal stability/test-retest reliability of the scale was evaluated by correlating scores from the first administration of the scale with those from the second, this being done using the Pearson correlation coefficient. Finally, in order to explore the criterion-related validity of the IDIS, scores from this scale were correlated with those obtained on the other four questionnaires by calculating the Pearson correlation coefficient. All analyses were performed using Statistical Package for the Social Sciences (SPSS) v.15, with a significance level of $\alpha=0.05$.

\subsection{Results}

Cronbach's $\alpha$ coefficient reached a value of 0.86 , which indicates good internal consistency (Kline, 2000). The analysis showed that the removal of any item would reduce the $\alpha$ coefficient to 0.82 .

Prior to conducting the factor extraction the Kaiser-Meyer-Olkin (KMO) index was calculated and Bartlett's test of sphericity (BTS) was applied. The KMO value of 0.846 and the significance of the BTS $\left(\chi^{2}=415.168 ; P<0.001\right)$ supported a reduction of dimensionality. A single factor was obtained with an eigen value of 3.531. This factor explained $58.85 \%$ of the variance, with item loadings ranging from 0.719 to 0.806 for item 6 and 4, respectively.

As shown in Table 1, the item-corrected total correlations ranged from 0.59 for item 6 ("For the last month or longer, I have found it difficult to socialise due to feeling tired or sleepy") to 0.70 for item 4 ("For the last month or longer, I have generally felt tired during the day"). These correlations indicate that the items fit well with the other items of the scale's only factor.
Table 1

Item-corrected total correlations and Cronbach's alpha in Spanish and English versions.

\begin{tabular}{lll}
\hline Item & Correlation item- corrected total & Alpha if item deleted \\
\hline 1 & $0.60 / 0.67$ & $0.84 / 0.93$ \\
2 & $0.67 / 0.75$ & $0.83 / 0.92$ \\
3 & $0.69 / 0.90$ & $0.83 / 0.90$ \\
4 & $0.70 / 0.78$ & $0.82 / 0.92$ \\
5 & $0.64 / 0.87$ & $0.84 / 0.91$ \\
6 & $0.59 / 0.80$ & $0.84 / 0.91$ \\
Alpha & $0.86 / 0.93$ & \\
\hline
\end{tabular}

Note: values of the English version are in italics.

The mean total score of the IDIS in the first administration was 6.38 (S.D. $=3.40$ ), with a range of 0 to 15 , while in the second it was 6.84 (S.D. $=3.82$ ), with a range of $1-14$. The correlation between the first and second administrations was 0.79 , which demonstrates adequate temporal stability/test-retest reliability of the scale (above the minimum threshold of 0.70 suggested by Kline (2000)).

Regarding criterion-related validity, the correlation coefficients obtained were between moderate and high. More specifically, the correlations for the total scores of the different scales ranged between 0.49 in the case of the BAI and 0.65 for the AIS-8. With regard to the GHQ-12 and the BDI, values of 0.57 and 0.60 , respectively, were obtained. The higher correlation with the AIS is noteworthy, because this scale is specifically designed to quantify sleep difficulties, thus supporting the convergent validity of the IDIS.

\subsection{Discussion}

This phase of the study explored the main psychometric properties of the Spanish version of the IDIS in terms of reliability estimates and evidence of validity. The scale shows good internal consistency and a single factor, termed 'insomnia diurnal consequences', explains almost $60 \%$ of the total variance observed. All the item loadings were high, suggesting that the items are very good indicators of the construct. Moreover, the instrument was found to have good item-total correlation indices and an adequate temporal stability. The correlations obtained with the AIS provide good support for the convergent validity of the scale. Furthermore, the correlations with the other scales provide additional support for a broad criterion-related validity, as they show that constructs which theoretically should be related to each other are indeed related. Taken together, these results provide good evidence for the validity of the IDIS and its ability to measure the intended construct in a sample of university students.

\section{Phase 3: Discriminant validity and decision validity regarding the screening accuracy of the IDIS}

\subsection{Overview}

The objective of this phase of the study was to explore the discriminant validity and decision validity regarding the screening accuracy of the IDIS, that is, its ability to differentiate between groups with and without insomnia, based on ICD-10 diagnostic criteria.

\subsection{Methods}

\subsubsection{Participants and procedure}

A total of 161 participants took part in this phase of the study: 82 from the community sample and 79 from the psychiatric population. The former comprised 27 primary healthcare patients recruited through general practitioners and 55 volunteers drawn from the social milieu of the principal investigator. The psychiatric group was recruited from among psychiatric outpatients attending routine visits at the Teknon Medical Centre (Barcelona) and the Parc Taulí Hospital (Sabadell). These 79 participants were mainly patients who met criteria on Axis I 
(particularly anxiety, depression and adjustment disorders) or nonclinical participants who met some Axis I criteria without fulfilling all the diagnostic criteria for a specific disorder. The exclusion criteria were cognitive impairment and inability to carry out written assignments.

All the above participants responded voluntarily to the IDIS and informed consent was always obtained. Of the total population who were initially invited to participate, less than $3 \%$ refused to do so. The presence of insomnia was established according to the non-organic diagnostic criteria of ICD-10. Table 2 shows sample characteristics regarding diagnoses (presence of an insomnia diagnosis or not), age and gender.

\subsubsection{Data analysis}

For both the community sample and psychiatric out-patients, total mean IDIS scores were compared between the groups with and without insomnia by means of the $t$-test for independent samples and Cohen's $d$. The sensitivity and specificity of the tool in terms of differentiating individuals with and without insomnia were analysed by means of receiver operating characteristic (ROC; Metz, 1978) curves.

\subsection{Results}

In the community sample, the mean IDIS score obtained by individuals with insomnia was significantly higher than that of those with no sleep problems $(\bar{X}=7.76$, S.D. $=3.73$ vs. $\bar{X}=4.43$, S.D. $=3.53$; $\left.t_{(80)}=3.906, P<0.05 ; d=0.91\right)$. The same pattern was observed in the group of psychiatric patients, where the mean score of those with insomnia $(\bar{X}=9.27$, S.D. $=4.17)$ was higher than that of individuals without this diagnosis $(\bar{X}=4.37$, S.D. $=3.39)$, this difference being statistically significant $\left(t_{(77)}=4.648, P<0.05 ; d=1.23\right)$.

With regard to the decision validity of the IDIS in the community sample, the area under the ROC curve (Fig. 1a) reached a value of $0.759(P<0.05)$, while in the group of psychiatric patients (Fig. 1b) the area defined by the ROC curve was $0.816(P<0.05)$. Both values can be regarded as good (Jaeschke et al., 2002).

The cut-off score in both samples was set at $>5$ out of a maximum of 18 . This yielded a sensitivity of $78 \%$ and a specificity of $57 \%$ in the community sample, and values of $83 \%$ and $63 \%$, respectively, in the psychiatric group. The sensitivity and specificity values showed an inverse variation with respect to one another, and the cut-off point reflects a compromise between the two. Taking into account that the IDIS is a screening test, the sensitivity values were given priority over those for specificity.

\subsection{Discussion}

The IDIS is shown to be capable of distinguishing between individuals with and without sleep problems concerning the diurnal impact of this problem, this being the case in both the community and psychiatric samples. Obviously, the relative utility of the sensitivity and specificity values depends on how a given measurement tool is used, which in the case of the IDIS will be as a screening tool. Although the sensitivity result is acceptable it should be noted that the sample size of the group employed in the ROC curve analysis is below the recommended minimum (Metz, 1978), which means that the results need to be corroborated with larger and other types of samples.

Table 2

Samples characteristics (diagnosis, age, gender).

\begin{tabular}{llllllll}
\hline & & \multicolumn{2}{l}{ Gender (\%) } & & Age & \\
\cline { 8 - 9 } \cline { 7 - 8 } \cline { 7 - 8 } Sample & $n$ & Males & Females & & Mean (SD) & Range \\
\hline Community without insomnia & 28 & 38.5 & 61.5 & & $46.69(15.67)$ & $20-75$ \\
Community with insomnia & 54 & 22.2 & 77.8 & & $42.70(14.51)$ & $20-79$ \\
Psychiatric without insomnia & 19 & 52.6 & 47.4 & & $40.27(8.36)$ & $28-55$ \\
Psychiatric with insomnia & 60 & 48.3 & 51.7 & & $39.85(12.36)$ & $19-72$ \\
\hline
\end{tabular}
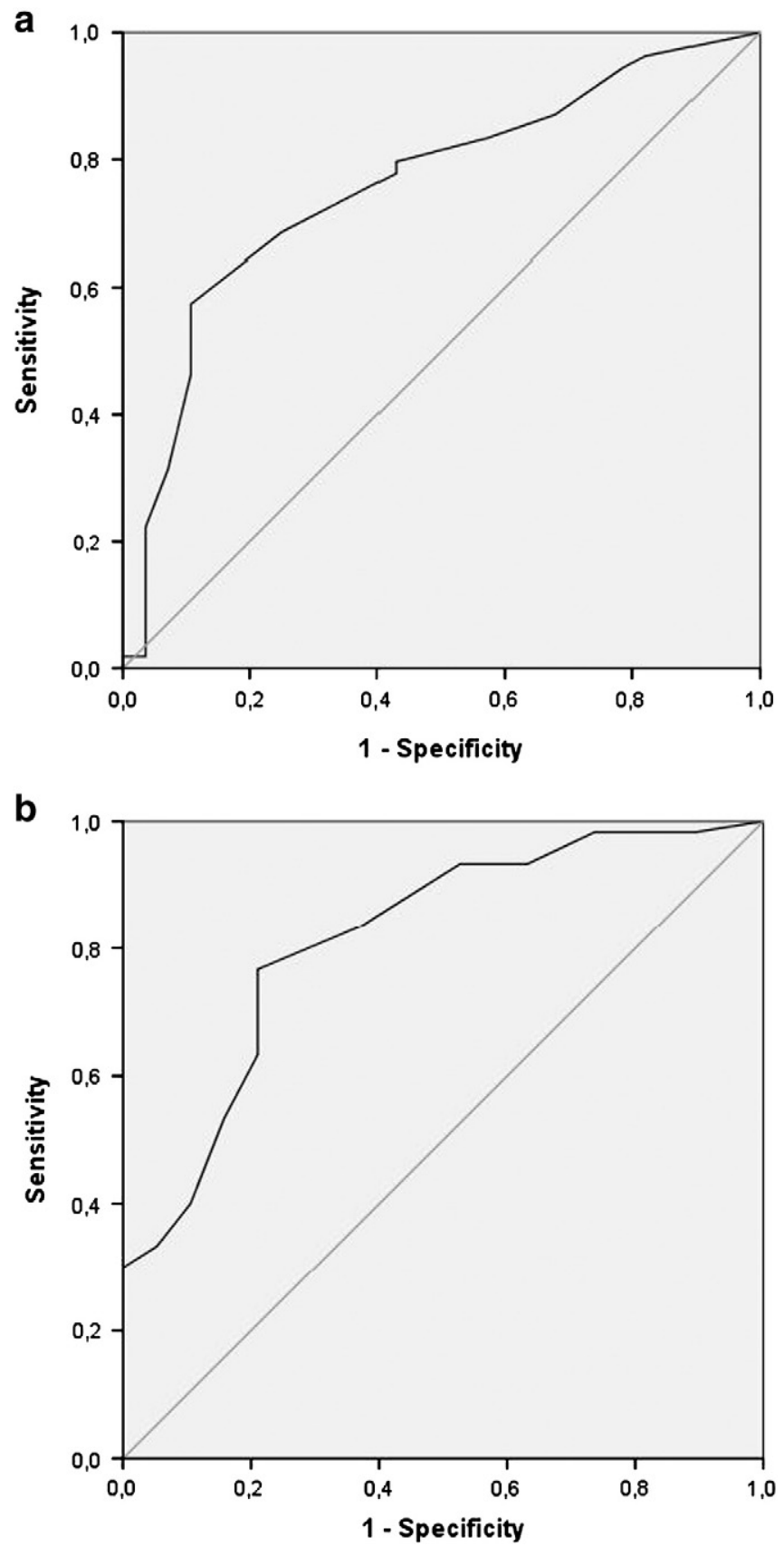

Fig. 1. ROC curve for the community sample (a) for the psychiatric sample (b).

\section{Phase 4: The English version of the IDIS}

\subsection{Overview}

The aim of this phase of the study was to develop an English version of the IDIS and present preliminary results regarding its psychometric properties.

\subsection{Methods}

\subsubsection{Participants and procedure}

To ensure equivalence between the original Spanish version and the new English version, a back-translation procedure was used. Thus, the Spanish scale was first translated into English, and this English version was then translated back into Spanish, before finally comparing the two Spanish versions (the original and the translated). This procedure was 
carried out by two English-language specialists (one native English speaker and one native Spanish speaker), both with extensive knowledge of the Spanish language. Each of them produced a separate translation. When comparing the two Spanish versions no substantial differences were found in the meaning of the items, and the proposed English version of the scale was therefore accepted (see Appendix 1b).

The sample for this phase of the study was recruited from among native English speakers or persons who had resided in Englishspeaking countries for at least 1 year. They were asked to participate voluntarily and to give their consent after being informed of the purpose of the study. Only $2 \%$ of those asked refused to participate. The scale was administered to 44 participants (21 men and 23 women) with a mean age of 43.26 years (S.D. $=11.20$; range $26-67$ ).

\subsubsection{Data analysis}

Internal consistency was assessed by means of Cronbach's $\alpha$ coefficient, while the item-corrected total correlation for IDIS items was based on the Pearson correlation between the item score and the corrected test score.

Scores on the Spanish and English versions of the IDIS were compared in the community sample for individuals with and without insomnia, following the diagnostic criteria of ICD- 10 .

\subsection{Results}

Cronbach's $\alpha$ coefficient for the English version gave a value of 0.93, which is excellent according to the criteria of Kline (2000). The analysis showed that eliminating any of the items would reduce the alpha coefficient to 0.90 . The item-corrected total correlation of the items (see Table 1) varied between 0.67 for item 1 ("For the last month or longerI have generally felt sleepy throughout the day") and 0.90 for item 3 ("For the last month or longer, I have found it difficult to concentrate during the day").

The overall mean IDIS score in the English sample was 5.66 (S.D. $=$ 3.92 ), with a mean score of 4.85 (S.D. $=4.25$ ) for the 20 individuals without insomnia and a mean score of 6.33 (S.D. = 3.58) among the 24 individuals with insomnia.

When comparing the IDIS total scores of the Spanish (see phase 2) and English versions for the community sample group without insomnia ( $n=28$ and $n=20$, respectively), the mean difference obtained was 0.42 , which was not statistically significant $\left(t_{(46)}=0.375 ; P=0.710\right)$. Specifically, the Spanish version yielded a mean score of 4.43 (S.D. $=$ 3.53) and the English version 4.85 (S.D. $=4.25$ ). The same comparison applied to individuals with insomnia $(n=54$ in the Spanish version and $n=24$ in the English version) gave a mean difference of 1.43, which was again not statistically significant $\left(t_{(76)}=1.578 ; P=0.119\right)$. Specifically, the mean score was 7.76 (S.D. $=3.73$ ) for the Spanish version and 6.33 (S.D. $=3.58$ ) for the English version.

\subsection{Discussion}

This phase of the study involved developing the English version of the IDIS and produced preliminary results regarding its psychometric properties. It is important to note the high values obtained for Cronbach's $\alpha$ coefficient and the item-corrected total correlations, as these support both the internal consistency of the scale and the high discriminative power of the items.

The comparison of IDIS scores obtained in the community sample with and without insomnia provides the first evidence of equivalence between the English and Spanish versions of the scale. Although the sample of English-speaking subjects is small, this preliminary study allows us to state that the English scale is likely to function in a very similar way to the Spanish scale. Obviously, further studies with larger sample sizes, which would enable an analysis of measurement invariance, are needed to corroborate these findings.

\section{General Discussion}

This article has described the validation of a new tool, the IDIS, using a large sample of individuals. The main psychometric properties of the original Spanish version of the IDIS are presented in terms of reliability estimates and evidence of validity, both of which proved to be very satisfactory.

When applied to a sample of students the IDIS showed adequate psychometric properties in terms of reliability and validity. First, the internal consistency of the IDIS was found to be very satisfactory $(\alpha=0.86)$, not only in itself but also in comparison to other standardised scales for measuring the diurnal consequences of insomnia or sleep difficulty. Indeed, the IDIS has an internal consistency similar to that (between 0.86 and 0.91 in two separate samples) of the Flinders Fatigue Scale (Gradisar et al., 2007), which measures daytime fatigue associated with insomnia. Furthermore, the IDIS yields a Cronbach's $\alpha$ coefficient similar to that reported $(\alpha=0.88)$ in the original reliability study of the ESS (Johns, 1991) and higher than the alpha value obtained in the study of reproducibility ( 0.78 and 0.82 in two different clinical settings) for the same scale (Nguyen et al., 2006). The ESS assesses daytime sleepiness, which is a diurnal symptom of insomnia. Regarding measures of sleep difficulty, the Cronbach's $\alpha$ for the AIS- 8 is 0.89 , which is again very similar to the result obtained here for the IDIS.

Moving on to the factor analysis, this revealed a single factor that explained almost $60 \%$ of the total variance observed, thereby demonstrating that the IDIS is a very compact scale, like other related scales with good psychometric properties, that is, the Flinders Fatigue Scale (Gradisar et al., 2007) and the AIS (Soldatos et al., 2000).

Third, the test-retest reliability of the IDIS was also very satisfactory, with a correlation coefficient of 0.79 . This indicates adequate temporal stability for the scale and is similar to that reported for other instruments. For instance, the test-retest reliability of the ESS in a sample of medical students was similarly high $(\alpha=0.82)$ (Johns, 1992), while that of the AIS-8 was even higher $(\alpha=0.89)$ (Soldatos et al., 2000).

Finally, the criterion-related validity of the IDIS was measured against the BDI, the BAI, the GHQ- 12 and the AIS- 8 . The correlations obtained between the IDIS and the other scales indicate that depression, anxiety and psychological/general well-being are all concepts related to insomnia. These findings are consistent with the literature (American Psychiatric Association, 2000; Riemann and Voderholzer, 2003; Novak et al., 2004; Johna et al., 2005; Hamilton et al., 2007), which reports that these manifestations often appear together, and they also corroborate the convergent validity of the IDIS with respect to the BDI, the BAI, the GHQ-12 and the AIS-8, thereby providing additional evidence of the scale's validity.

In conclusion, the results regarding the psychometric properties of the IDIS confirm its suitability for measuring the diurnal consequences of insomnia in a sample of students.

When applied to the community and psychiatric samples, the IDIS was shown to be capable of discriminating individuals with and without insomnia. The area under the ROC curve can be interpreted as the average sensitivity of the test for all possible values of specificity, and the results obtained for the IDIS are good according to the criteria of Jaeschke et al. (2002). Specifically, the values obtained corresponded to adequate indices of sensitivity and specificity in the community sample (78\% and 57\%, respectively) and high ones in the group of psychiatric patients (83\% and 63\%, respectively). The sensitivity values support the decision validity of the instrument, which is always a requirement for a screening tool such as the IDIS. Although the specificity values are lower they would still support the decision validity of the tool, as detected cases would then undergo a detailed clinical analysis. Whenever a test is to be used for screening purposes the cut-off point chosen must imply greater sensitivity, as what is most important is to obtain as few false negatives as possible. The cases thus identified would then be analysed in depth in order to refine the diagnosis, thereby reducing the number of false positives 
and enabling the most suitable intervention to be chosen. The results obtained here therefore demonstrate the usefulness of the scale for both primary care and mental health contexts.

Regarding the English version of the scale, this has been developed in order to facilitate cross-cultural comparisons and to provide a valid scale for measuring the diurnal impact of insomnia in an Englishspeaking population. The preliminary results indicate that the English version has both good internal consistency (Cronbach's $\alpha$ coefficient of 0.93 ) and item discrimination indices. These results are promising and suggest that the English and Spanish versions of the scale will function in a similar way. Clearly, however, the small sample size used in this phase of the study means that further research is now required with larger samples in order to corroborate the comparative results obtained.

\section{Conclusions, limitations and future research}

The problem of insomnia involves not only nocturnal processes but, and perhaps more importantly, its effects on daily functioning. In this regard, several studies have demonstrated the need to address daytime factors in the progression and maintenance of this disorder. Indeed, those who suffer from insomnia tend to focus on the diurnal consequences of their sleep difficulty (Marchini et al., 1983; Moul et al., 2002; Ellis et al., 2007), and some of the most commonly reported symptoms are fatigue, sleepiness or difficulty in functioning adequately during the day.

The rationale for the development of the IDIS was based on the need to provide a screening tool to assess the daytime impact of sleep disruption. The IDIS is a simple instrument that is easy to administer and shorter than other widely used scales for evaluating aspects related to insomnia. This makes it suitable both for epidemiology studies and as an initial screening tool in clinical contexts. In addition to these research and clinical applications it is, to the best of our knowledge, the first scale in Spanish that specifically assesses the daytime consequences of this sleep disorder. Concerning these practical applications of the IDIS, it can be argued that a better understanding of diurnal processes in individuals with a sleep complaint provides an opportunity to address specific aspects of daytime functioning. In addition, the scale provides a quantitative index that can contribute to the design of specific interventions, thereby optimising the treatment of the diurnal consequences of insomnia.

Although a number of positive outcomes from this preliminary study of the IDIS have already been mentioned, certain limitations must also be acknowledged. First, whilst all efforts were made to maintain objectivity in developing this measuring tool, it is not possible to eliminate the subjective interpretation of participants' responses, since the assessments are derived exclusively from self-report questionnaires. Although subjective ratings are frequently used in sleep-related studies, it would be interesting to compare these responses with those obtained through objective measurement tools. Second, the sample is not representative of our population because probabilistic sampling methods were not used for the selection process. In addition, the sample size in some of the analysed groups is rather small and this may affect some of the results (i.e., ROC curves). Hence, there is a need to accumulate additional evidence of this instrument's value with larger samples. Regarding the English version of the scale, it has already been stated that the results are very promising. However, further validity studies with larger samples are nonetheless needed, particularly in the English-speaking population with sleep complaints. Another important direction in future research lies in directly determining whether the IDIS, as an assessment tool, is sensitive to therapeutic intervention. Such research would have the potential to reveal a therapeutic effect and, hopefully, an improvement in the diurnal symptoms of individuals after undergoing an insomnia intervention.

In conclusion, the IDIS is a brief and reliable measure that has been validated in various samples, supporting its use to assess the daytime consequences of insomnia. Furthermore, its ability to discriminate individuals with and without insomnia makes it suitable as a screening tool. The information it provides may also contribute to the design of specific treatment interventions. The specific factors assessed by the IDIS shed light on the daytime effects of insomnia, and its good psychometric properties and simplicity make it a valuable instrument for use in a large variety of clinical and research settings.

\section{Acknowledgements}

This study was supported by grant 2009SGR00822 from the Departament d'Universitats, Recerca i Societat de la Informació of the Generalitat de Catalunya.

\section{Appendix 1. Spanish (a) and English (b) versions of the Insomnia Diurnal Impact Scale}

\begin{tabular}{|c|c|c|c|c|c|}
\hline \multicolumn{2}{|c|}{ ENUNCIADOS } & \multirow{2}{*}{$\begin{array}{l}\text { Totalmente } \\
\text { en desacuerdo }\end{array}$} & \multirow{2}{*}{$\begin{array}{l}\text { En } \\
\text { desacuerdo }\end{array}$} & \multirow{2}{*}{$\begin{array}{l}\text { De } \\
\text { acuerdo } \\
2\end{array}$} & \multirow{2}{*}{$\begin{array}{l}\begin{array}{l}\text { Totalmente } \\
\text { de acuerdo }\end{array} \\
3\end{array}$} \\
\hline 1 & $\begin{array}{l}\text { Desde hace al menos un } \\
\text { mes, me siento } \\
\text { habitualmente } \\
\text { somnoliento durante el día }\end{array}$ & & & & \\
\hline 2 & $\begin{array}{l}\text { Desde hace al menos un } \\
\text { mes, me siento } \\
\text { habitualmente irritado }\end{array}$ & 0 & 1 & 2 & 3 \\
\hline 3 & $\begin{array}{l}\text { Desde hace al menos un } \\
\text { mes, me cuesta } \\
\text { concentrarme durante el } \\
\text { día }\end{array}$ & 0 & 1 & 2 & 3 \\
\hline 4 & $\begin{array}{l}\text { Desde hace al menos un } \\
\text { mes, me siento } \\
\text { habitualmente fatigado } \\
\text { durante el día }\end{array}$ & 0 & 1 & 2 & 3 \\
\hline 5 & $\begin{array}{l}\text { Desde hace al menos un } \\
\text { mes, tengo dificultades } \\
\text { para efectuar mis } \\
\text { actividades cotidianas }\end{array}$ & 0 & 1 & 2 & 3 \\
\hline 6 & $\begin{array}{l}\text { Desde hace al menos un } \\
\text { mes, me cuesta } \\
\text { relacionarme por sentirme } \\
\text { somnoliento o fatigado }\end{array}$ & 0 & 1 & 2 & 3 \\
\hline \multicolumn{6}{|c|}{ b) English version: Insomnia Diurnal Impact Scale } \\
\hline & ATEMENTS & $\begin{array}{l}\text { Totally } \\
\text { disagree }\end{array}$ & Disagree & Agree & $\begin{array}{l}\text { Totally } \\
\text { agree }\end{array}$ \\
\hline 1 & $\begin{array}{l}\text { For the last month or } \\
\text { longer, I have generally felt } \\
\text { sleepy throughout the day }\end{array}$ & 0 & 1 & 2 & 3 \\
\hline 2 & $\begin{array}{l}\text { For the last month or } \\
\text { longer, I have generally } \\
\text { felt irritable }\end{array}$ & 0 & 1 & 2 & 3 \\
\hline 3 & $\begin{array}{l}\text { For the last month or } \\
\text { longer, I have found it } \\
\text { difficult to concentrate } \\
\text { during the day }\end{array}$ & 0 & 1 & 2 & 3 \\
\hline 4 & $\begin{array}{l}\text { For the last month or } \\
\text { longer, I have generally } \\
\text { felt tired during the day }\end{array}$ & 0 & 1 & 2 & 3 \\
\hline 5 & $\begin{array}{l}\text { For the last month or } \\
\text { longer, I have found it } \\
\text { difficult to carry out my } \\
\text { daily tasks }\end{array}$ & 0 & 1 & 2 & 3 \\
\hline 6 & $\begin{array}{l}\text { For the last month or } \\
\text { longer, I have found it } \\
\text { difficult to socialize due to } \\
\text { feeling tired or sleepy }\end{array}$ & 0 & 1 & 2 & 3 \\
\hline
\end{tabular}




\section{References}

Alapin, I., Fichten, C.S., Libman, E., Creti, L., Bailes, S., Wright, J., 2000. How is good and poor sleep in older adults and college students related to daytime sleepiness, fatigue, and ability to concentrate? Journal of Psychosomatic Research 49, 381-390.

American Academy of Sleep Medicine, 2005. International Classification of Sleep Disorders: Diagnostic and Coding Manual, 2nd edition. American Academy of Sleep Medicine, Westchester.

American Psychiatric Association, 2000. Diagnostic and Statistical Manual of Menta Disorders, revised (DSM-IV-R), 4th edition. APA, Washington D.C.

Beck, A.T., Rush, A.J., Shaw, B.F., Emery, G., 1979. Cognitive Therapy of Depression. Guilford Press, New York

Beck, A.T., Emery, G., Greenberg, R.L., 1985. Anxiety Disorders and Phobias: A Cognitive Perspective. Basic Books, New York.

Breslau, N., Roth, T., Rosenthal, L., Andreski, P., 1996. Sleep disturbance and psychiatric disorders: a longitudinal epidemiological study of young adults. Biologica Psychiatry 39 (6), 411-418.

Buysse, D.J., Reynolds, C.F., Monk, T.H., Berman, S.R., Kupfer, D.J., 1989. The Pittsburgh Sleep Quality Index: a new instrument for psychiatric practice and research. Psychiatry Research 28, 193-213.

Ellis, J., Mitchell, K., Hogh, H., 2007. Sleep preoccupation in poor sleepers: Psychometric properties of the Sleep Preoccupation Scale. Journal of Psychosomatic Research 63, 579-585.

Goldberg, D.P., 1972. The Detection of Psychiatric Illness by Questionnaire. Oxford University Press, London.

Gradisar, M., Lack, L., Richards, H., Harris, J., Gallasch, J., Boundy, M., 2007. The Flinder Fatigue Scale: Preliminary psychometric properties and clinical sensitivity of a new scale for measuring daytime fatigue associated with insomnia. Journal of Clinical Sleep Medicine 3, 722-728.

Hamilton, N.A., Catley, D., Karlson, C.,2007. Sleep and affective response to stress and pain. Health Psychology 26 (3), 288-295.

Harvey, A.G., 2002. A cognitive model of insomnia. Behaviour Research and Therapy 40, 869-893.

Hoddes, E., Zarcone, V., Smythe, H., Phillips, K., Dement, W.C., 1973. Quantification of sleepiness: a new approach. Psychophysiology 10, 431-437.

Jaeschke, R., Guyatt, G., Lijmer, J., 2002. Diagnostic tests. In: Guyatt, G., Rennie, D. (Eds.), Users' Guides to the Medical Literature. AMA Press, Chicago, pp. 121-140.
Johna, U., Meyera, C., Rumpfb, H.J., Hapke, U., 2005. Relationships of psychiatric disorders with sleep duration in an adult general population simple. Journal of Psychiatric Research 39 (6), 577-583.

Johns, M.W., 1991. A new method for measuring daytime sleepiness: The Epworth Sleepiness Scale. Sleep 14, 540-545.

Johns, M.W., 1992. Reliability and factor analysis of The Epworth Sleepiness Scale. Sleep $15,376-381$.

Kline, P., 2000. The Handbook of Psychological Testing, 2nd ed. Routledge, London and New York.

Marchini, E.J., Coates, T.J., Magistad, J.G., Waldum, S.J., 1983. What do insomniacs do, think and feel during the day? A preliminary study. Sleep 6, 147-155.

Metz, C.E., 1978. Basic principles of ROC analysis. Seminars in Nuclear Medicine 8, 283-298.

Morin, C.M., 1993. Insomnia: Psychological Assessment and Management. The Guildford Press, New York.

Morin, C.M., 2000. The nature of insomnia and the need to refine our diagnostic criteria. Psychosomatic Medicine 62, 483-485.

Morin, C.M., Kowatch, R.A., Barry, T., Walton, E., 1993. Cognitive-behaviour therapy for late-life insomnia. Journal of Consulting and Clinical Psychology 61, 137-146.

Moul, D.E., Nofzinger, E.A., Pilkonis, P.A., Houck, P.R., Miewald, J.M., Buysse, D.J., 2002. Symptom reports in severe chronic insomnia. Sleep 25, 553-563.

Nguyen, A.T.D., Baltzan, M.A., Small, D., Wolkove, N., Guillon, S., Palayew, M., 2006. Clinical reproducibility of the Epworth Sleepiness Scale. Journal of Clinical Sleep Medicine 2 (2), 170-174.

Novak, M., Mucsi, I., Shapiro, C.M., Rethelyi, J., Kopp, M.S., 2004. Increased utilization of health services by insomniacs - An epidemiological perspective. Journal of Psychosomatic Research 56 (5), 527-536.

Parrott, A.C., Hindmarch, I., 1978. Factor analysis of a sleep evaluation questionnaire. Psychological Medicine 8, 325-329.

Riemann, D., Voderholzer, U., 2003. Primary insomnia: a risk factor to develop depression. Journal of Affective Disorders 76 (1-3), 255-259.

Soldatos, C.R., Dikeos, D.G., Paparrigopoulos, T.J., 2000. Athens Insomnia Scales: validation on an instrument based on ICD - 10 criteria. Journal of Psychosomatic Research 48, 555-560.

World Health Organization, 1994. The ICD - 10 Classification of Mental and Behavioural Disorders. World Health Organization, Geneva.

Zammit, G.K., Weiner, J., Damato, N., Sillup, G., McMillan, C.H., 1999. Quality of life in people with insomnia. Sleep 22, 379-385. 